\title{
Modelling Impacts of Socio-Economic Factors on Temporal Diffusion of PV-Based Communal Grids
}

\author{
Nicholas Opiyo \\ Energy Research Institute, SCAPE, University of Leeds, Leeds, UK \\ Email: elno@leeds.ac.uk
}

Received 3 December 2015; accepted 27 December 2015; published 30 December 2015

Copyright (C) 2015 by author and Scientific Research Publishing Inc.

This work is licensed under the Creative Commons Attribution International License (CC BY). http://creativecommons.org/licenses/by/4.0/

\begin{abstract}
Impacts of socio-economic factors on temporal diffusions of solar electricity microgeneration systems in a rural developing community are modelled and simulated using an agent-based model (ABM). ABMs seek to capture the overall macro-effects of different micro-decisions in a virtual world; they model individual entities within a complex system and the rules that govern them to capture the overall effects of their interactions. Results showed that falling PV costs coupled with generally increasing grid electricity costs would lead to increased uptake of PV systems in such communities. On the other hand, high lending rates in most developing nations would stifle use of credit facilities in purchases of PV systems and thus diminishing their uptakes. Results also showed that introduction of favourable government policies in forms of subsidies would strongly stimulate PV installations in such communities. Social acceptance is important for diffusion of any new technology into a given market and more so with solar systems; results show that neighbourhood influence plays major roles in PV diffusions with many households installing PV systems if their neighbours within a given sensing radius do the same. Results also showed that requiring a certain percentage of neighbours to have installed PV before a household considered doing the same could have negative effects on PV installations as decisions to install PV are influenced by many independent and dependent factors and not by neighbourhood threshold alone.
\end{abstract}

\section{Keywords}

PV Diffusion, Developing Community, Economic Factors, Social Factors, Political Factors

\section{Introduction}

Development of electricity delivery infrastructures are path-dependent, meaning, each development decision and 
step affects subsequent steps, and the final outcome. Human actors are therefore the most important variables in any energy development plan as their decisions affect the way a system evolves. Proper policy-planning tools are therefore required to guide decision-makers on least cost rural electrification pathways. Many factors influence choices of technologies used in rural electrification, the main ones being availability of resources, demand, investment costs, and local socio-political and cultural environments. Different modelling tools and techniques have been applied in planning rural electrification paths in many countries. However, these often view this problem as a question of expansion of grid coverage through extensions of existing transmission and distribution lines from central power generation stations and seldom address the unique and regionally-specific challenges presented by many developing nations [1]-[3]. In most of sub-Saharan Africa, for example, grid electricity is often unreliable, plagued with frequent blackouts, poor maintenance, and low quality of service. In these regions, expansions of the national grids often result in further strain on the systems and thus in further reduction in quality of services to those already grid-connected [4]. Bhattacharyya and Timilsina point to models that can capture a developing nation's unique contexts as a key input for future policy formulation while Urban et al. point to the lack of focus on off-grid technologies based on locally available renewable energy resources and on the prevailing socio-economic and cultural factors [5] [6].

In this work, an Agent-Based Model (ABM) is developed as a tool for evaluating temporal diffusion of PV-based communal grids to provide decision-makers with a user-friendly environment for PV-based rural electrification policy development, planning, and implementation. The model takes into account the complexities and limitations of solar electricity microgeneration technologies, decisions by human actors, geographical factors, and interaction between the three factors. ABMs seek to capture the overall macro-effects of different micro-decisions in a virtual world; they model individual entities within a complex system and the rules that govern the interactions of the entities within the system, to capture the overall effect of such interactions. The model developed in this work considers a "clean-slate" scenario where a village has no existing PV installations. Such a village is randomly seeded with basic solar electricity microgeneration systems and temporal observations are made as the seeds grow and branch out into various electrification topologies, based on step-decisions by human actors, and on other factors such as neighbourhood influence, government policies, technical factors, and costs.

\section{Methodology}

Netlogo was chosen for this work because it is user friendly, free, and easy to learn and modify, and is also widely recognized as the best tool for agent-based modelling. The following agents are created in the model: a) a representation of the environment and the solar potential in it; b) the populations in it that require electricity; c) PV seeds that would use the environment to produce electricity; d) links to join PV systems together into communal grids; and e) a central observer or stakeholder who determines the strategies and preferences for PV diffusions. Through these agents and the rules created for their interactions, the model is used to simulate the way decisions and preferences by human actors, based on socio-economic factors, affect temporal diffusion of PV microgeneration systems and PV-based communal grids in a typical rural developing community. Locationspecific data is used to create realistic environments and heterogeneous agents in the model, e.g. population, solar potential, etc. Data on the specific technical performance and economics of solar microgeneration systems is also added to the model.

A house without PV must first develop the idea to install PV given the following factors amongst others: a) cost; b) neighbourhood influence; c) government policies such as subsidies; and d) social pressure (advertisements). To calculate the idea to install PV (PVD), the above factors are combined as follows [7]

$$
P V D=\sum_{i=1}^{n} W_{i} F_{i}
$$

where $n$ is the total numbers of factors, $W_{i}$ is the weight associated with each factor $F_{i}$, and each $F_{i}$ has a value between 0 and 1 and

$$
\sum_{i=1}^{n} W_{i}=1
$$

Idea to install PV returns true if 


$$
\frac{H P V_{S R}}{T H_{S R}} \times 100>N T
$$

where $H P V_{S R}$ is the number of houses with $\mathrm{PV}$ within a given sensing radius $(S R)$ or neighbourhood, $T H_{S R}$ is the total number of houses within the same sensing radius, and $N T$ is the neighbourhood threshold, minimum percentage of neighbours within the sensing radius who must have installed SHS for a household to develop the same. if:

If the idea to install SHS returns true, cost comparison is done before a final decision is made. PV is installed

$$
P V G C_{k W h}<A V C_{k W h}+S_{k W h}
$$

where $P V G C_{k W h}$ is the $\mathrm{PV}$ generation cost per $\mathrm{kWh}, A V C_{k W h}$ is avoided cost per $\mathrm{kWh}$, and $S_{k W h}$ is subsidies per kWh.

Avoided cost per $\mathrm{kWh}, A V C_{k W h}$ is given by

$$
A V C_{k W h}=N G C_{k W h}
$$

where $N G C_{k W h}$ is the prevailing national grid electricity cost per $\mathrm{kWh}$.

$\mathrm{PV}$ generation cost per $\mathrm{kWh}\left(P V G C_{k W h}\right)$ is given by

$$
P V G C_{k W h}=\frac{P V C_{T}}{(P V O \times P V L)}
$$

where $P V C_{T}$ is the total PV cost, $P V O$ is the total PV output, and $P V L$ is PV lifetime.

Total $\mathrm{PV}$ cost $\left(P V C_{T}\right)$ is given by

$$
P V C_{T}=\left(P V C_{m^{2}}-S_{m^{2}}\right) \times P V \varepsilon \times R S \times A F
$$

where $P V C_{m^{2}}$ is PV cost per $\mathrm{m}^{2}, S_{m^{2}}$ is subsidies per $\mathrm{m}^{2}, P V \varepsilon$ is PV efficiency, $R S$ is roof size available under PV Installation and ranges between $10 \mathrm{~m}^{2}$ and $50 \mathrm{~m}^{2}$, and $A F$ is an accounting factor given by

$$
A F=(1+r)^{P V L}
$$

where $r$ is the discount rate and $P V L$ is the PV lifetime.

If there are no functional subsidies policies, $S_{m^{2}}$ and $S_{k W h}$ are set to zero. Total PV output PVO is given by

$$
P V O=I \times P Q \times P V \varepsilon \times R S
$$

where $P V \varepsilon$ is $\mathrm{PV}$ efficiency, $R S$ is roof size, $P Q$ is the patch-quality (landscape quality) and depends on topography and prevailing climatic conditions, and $I$ in $\mathrm{W} / \mathrm{m}^{2}$ is the insolation and is given by

$$
I=600+\left[1000 \times p r \times \frac{(1-\cos \theta)}{2}\right]
$$

where $\theta$ is the orientation angle while $p r$ is the particle reduction factor, a factor used to calculate reduction in aerosol particles which scatter solar radiation. It depends on location and prevailing climatic and weather conditions.

To be allowed to join a communal grid, a house must have installed PV of a given minimum capacity (powerthreshold) and be within a given sensing radius of other homes with PV that meet the power-threshold. The idea to join a communal grid $(C g D)$ returns true if

$$
\frac{H C g P T_{C S R}}{T H_{C S R}} \times 100>C g T
$$

where $H C g P T_{C S R}$ is the number of houses with PV within a given communal grid sensing radius that meet the 
power-threshold ( $\mathrm{CgPT}$ ), $\mathrm{TH}_{\mathrm{CSR}}$ is the total number of houses within the same sensing radius, and $\mathrm{CgT}$ is the communal grid neighbourhood threshold, minimum percentage of neighbours with PV that meet the CgPT required within the sensing radius for a household to think about joining a communal grid. Communal grid sensing radius (CSR) is the radius within which a household can sense its neighbours. It depends on location and population density.

The following values, based on current market values in Kenya, are used for this model: PV Efficiency ( $P V \varepsilon$ ) $=15 \%$, PV Lifetime $(P V L)=25$ Years, PV Cost per $\mathrm{m}^{2}\left(P V C_{\mathrm{m}^{2}}\right)=\$ 300 / \mathrm{m}^{2}$, and National Grid Electricity Cost per kWh $\left(N G C_{k W h}\right)=\$ 0.20 / \mathrm{kWh}$. A sample of 2500 houses, $0.1 \%$ of which are randomly seeded with PV, is used in all simulations and then impacts of the following factors are explored: a) subsidies, b) neighbourhood influence, c) lending rates, and d) power threshold.

\section{Results and Discussion}

Figure 1 shows the world (view) after 50 years. The landscape is coloured green with the lighter areas being hill tops. Black houses are those without PV and are thus presumed to be unelectrified. Houses deciding on installing PV are coloured white while those that have installed PV are coloured yellow. Houses with PV that meet the cgrid-power-threshold and are deciding on joining communal grids are coloured red. Houses that have joined communal grids are coloured blue and are linked to other houses in the communal grid through purple links (grid lines).

\subsection{Impacts of Subsidies on PV Diffusions}

Studies show that positive government incentives and subsidies are largely responsible for rapid growth in PV installations in developed nations which have proper market and technical infrastructures necessary for implementations of such policies; Beise's research on diffusions of technologies across national boundaries found that positive government policies significantly stimulated diffusion of PV across many countries, underscoring the importance of government intervention in adaptations of new technologies [8]. A comparable study by Guidolin et al. also found that positive government policies in form of incentives and subsidies positively influenced PV

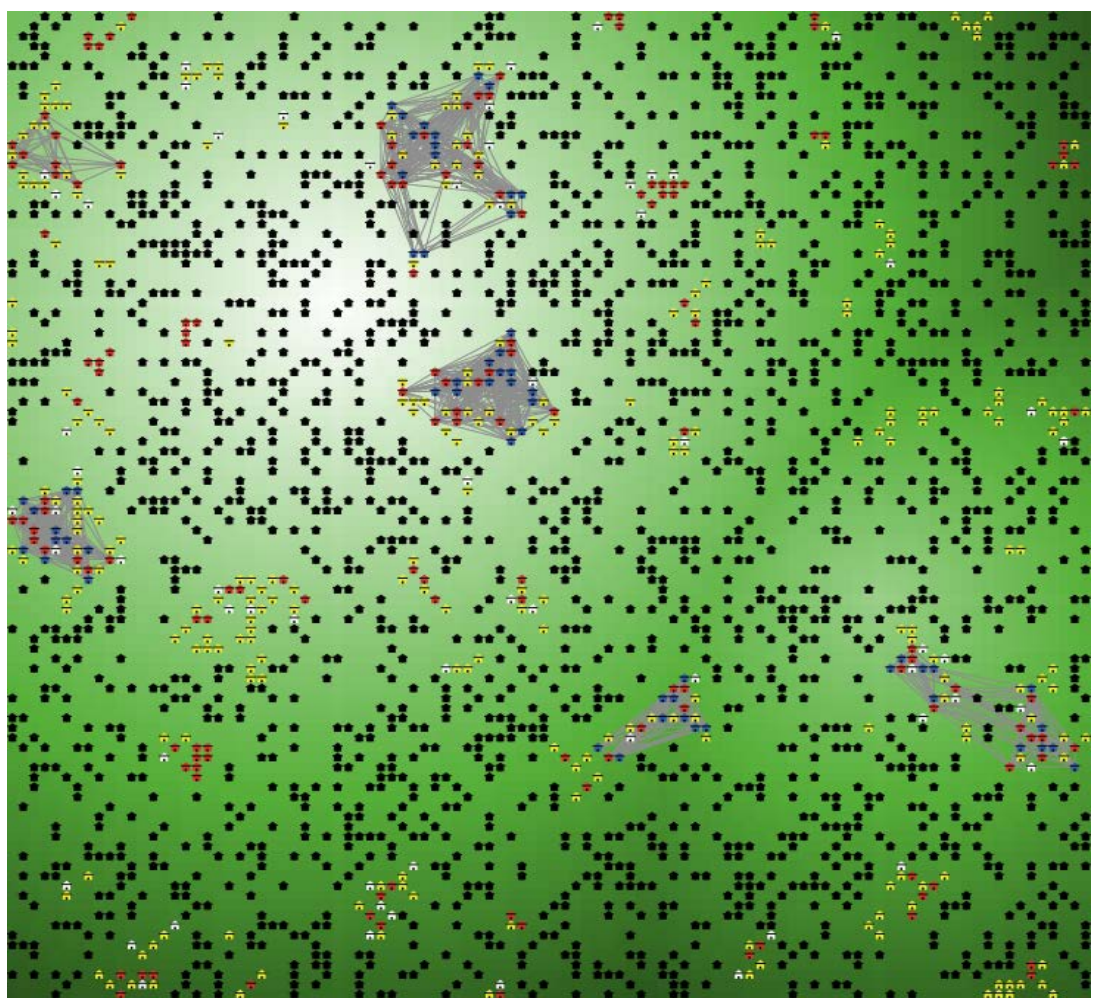

Figure 1. A view of the world after simulations. 
diffusions across 11 countries [9]. Wustenhagen found that positive government policies, especially feed-in-tariffs (FiT), were largely responsible for the boom in PV installation in Germany [10]. Zhang et al. found that in addition to positive regional governments' policies, costs also played significant roles in PV diffusions across Japan [11]. In developing nations on the other hand, limited resources restrict governments' abilities to subsidize new technologies as priorities are given to crucial projects. In this section, impacts of subsidies per kWh of PV electricity generated and subsidies per $\mathrm{m}^{2}$ of PV Installed on the diffusions of PV systems in an equatorial-belt rural developing community are investigated.

\section{Subsidies per kWh of PV Power Generated}

Figure 2 shows a comparison of households with PV installations and of households connected to communal grids as functions of increasing subsidies $/ \mathrm{kWh}$ after 50 years. As subsidies $/ \mathrm{kWh}$ increase, the number of households installing PV and the number of households forming or joining communal grids grow. Specifically, with no subsidies, only about 550 (22\%) households will have installed PV after 50 years. With subsidies of $\$ 0.1 / \mathrm{kWh}$, about 629 (25.2\%) households will have install PV, representing an increase of $14.4 \%$ in PV installations. With subsidies of $\$ 0.2 / \mathrm{kWh}$, about 744 (29.8\%) households will have install PV, representing an increase of $35.3 \%$ in PV installations. And with subsidies of $\$ 0.3 / \mathrm{kWh}$, about 900 (36\%) households will have install PV, representing an increase of $63.6 \%$ in PV installations. There is therefore an exponential growth in households installing PV as subsidies increase.

Similarly, with no subsidies, only about 115 households with PV would have joined communal grids, representing $20.9 \%$ of households with PV. With subsidies of $\$ 0.1 / \mathrm{kWh}$, about 159 households with PV, or $25.3 \%$, will have joined communal grids, representing an increase of $38.3 \%$. With subsidies of $\$ 0.2 / \mathrm{kWh}$, about 196 households with PV, or $26.3 \%$, will have joined communal grids, representing an increase of $70.4 \%$. And with subsidies of $\$ 0.30 / \mathrm{kWh}, 263$ households with PV, or $29.2 \%$, would have joined communal grids, representing an increase of $128.7 \%$. Subsidies $/ \mathrm{kWh}$ therefore stimulate PV installations, with installations exponentially increasing with increasing subsidies. Also, increasing PV installations translate into more households forming or joining communal grids, an indication of increasing capacities in installed PV systems.

Figure 3 compares temporal growth in power outputs from households with PV installations (blue) and from households connected to communal grids (red) as function of different subsidies/kWh. With no subsidies,

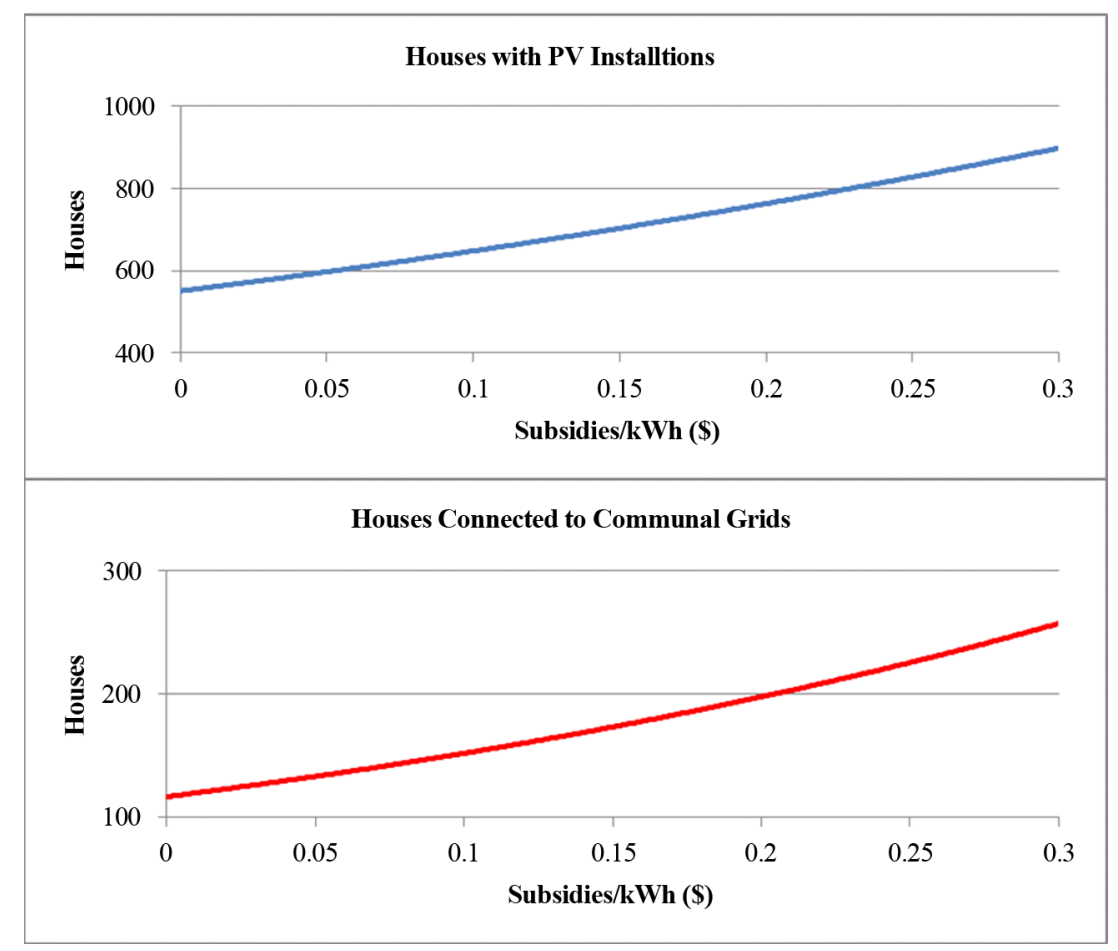

Figure 2. Effects of subsidies/kWh on PV and communal grids diffusions. 


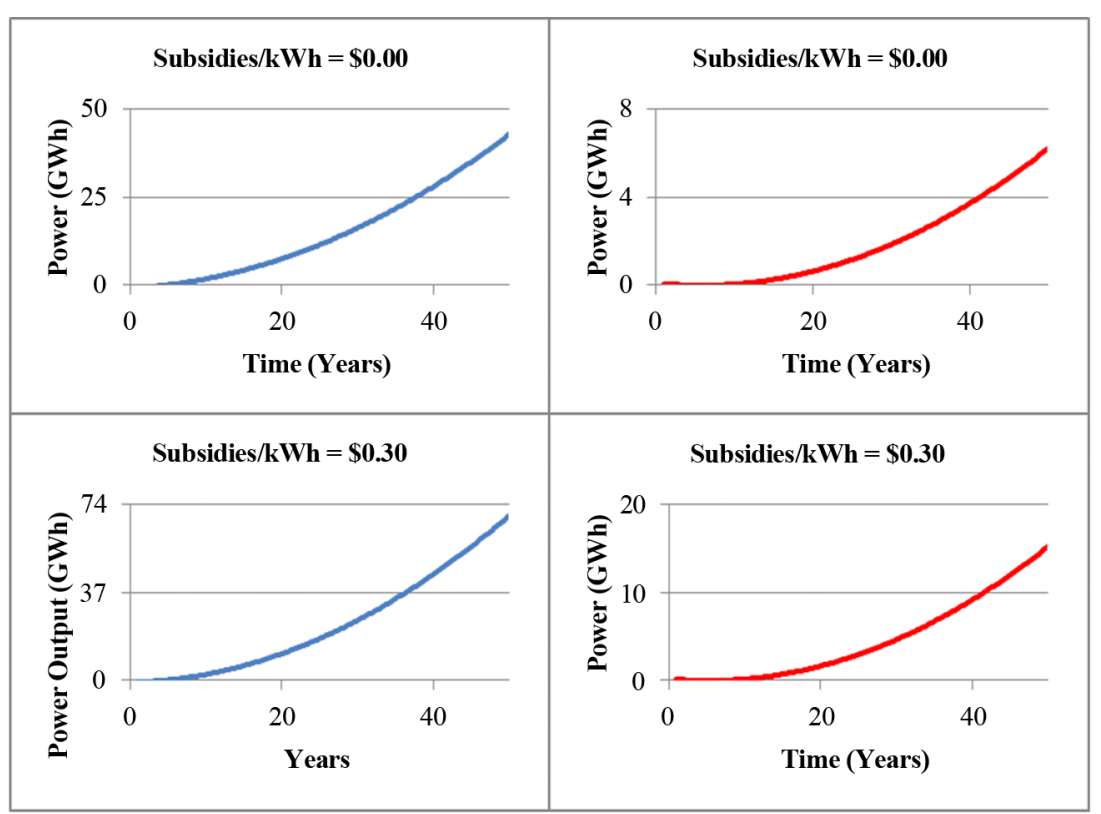

Figure 3. Temporal growths in power outputs from PV (blue) and communal grids (red).

households with PV generate about 43 GWh of electricity while communal girds generate about 6.1 GWh of electricity. With subsidies of $\$ 0.30 / \mathrm{kWh}$, households with PV generate about $67.8 \mathrm{GWh}$ of electricity, representing an increase of $57.7 \%$ in power output. Similarly, with subsidies of $\$ 0.30 / \mathrm{kWh}$, households connected to communal grids generate about 14.2 GWh of electricity, representing an increase of $132.8 \%$ in power output. The huge increase in power output from communal grids point to increase in installed PV capacities for those joining communal grids. These results further validate impacts of subsidies/kWh on PV installations.

Figure 4 shows a comparison of households with PV installations and of households connected to communal grids. As with subsidies/kWh, the number of households with PV installations, and those with PV that are getting connected to communal grids, grows with subsidies $/ \mathrm{m}^{2}$. Specifically, with no subsidies, the number of households with PV grows from $3 \%$ or $0.1 \%$ to about $550 \%$ or $22 \%$ of all households. If a subsidy of $\$ 100 / \mathrm{m}^{2}$ is introduced, the number of households with PV grows to about $650 \%$ or $26 \%$ of all households, representing an increase of $18.2 \%$ in PV installations. A similar trend is seen for higher subsidies with subsidies of $\$ 200 / \mathrm{m}^{2}$ leading to $800 \%$ or $32.5 \%$ of all households having installed PV, representing an increase of $45.5 \%$ in PV installations. Similarly, subsidies of $\$ 250 / \mathrm{m}^{2}$ lead to about $902 \%$ or $36 \%$ households having installed PV, representing an increase of $64 \%$ in PV installations.

A similar trend is observed in households getting connected to communal grids; with no subsidies, the number of households connected to communal grids grows from 0 to about 93 after 50 years, representing $16.9 \%$ of households with PV. If a subsidy of $\$ 100 / \mathrm{m}^{2}$ is introduced, this number grows to about 121 , representing $18.6 \%$ of households with PV and an increase of $30.1 \%$ in houses connected to communal grids. With subsidies of $\$ 200 / \mathrm{m}^{2}$, the number of households connected to communal grids grows to 204 , representing $25.5 \%$ of households withPV. This represents an increase of $119.4 \%$ in households connected to communal grids. Similarly, subsidies of $\$ 250 / \mathrm{m}^{2}$ leads to over 269 households having joined communal grids, representing $29.8 \%$ of households with PV and an increase of $189.2 \%$ in houses connected to communal grids. Huge growths in houses connecting to communal grids are indicative of increasing power demands, most likely stimulated by increasing subsidies. Subsidies $/ \mathrm{m}^{2}$ therefore stimulated PV installations, and subsequent connections to communal grids, just as with subsidies $/ \mathrm{kWh}$.

Figure 5 compares temporal growth in power outputs from households with PV installations (blue) and from households connected to communal grids (red) as functions of different subsidies $/ \mathrm{m}^{2}$. With no subsidies, households with PV generate about $43 \mathrm{GWh}$ of electricity while communal girds generate about $6.1 \mathrm{GWh}$ of electricity. With subsidies of $\$ 250 / \mathrm{m}^{2}$, households with PV generate about $69.5 \mathrm{GWh}$ of electricity, representing an increase of $61.6 \%$ in power output. Similarly, with subsidies of $\$ 250 / \mathrm{m}^{2}$, households connected to communal grids 


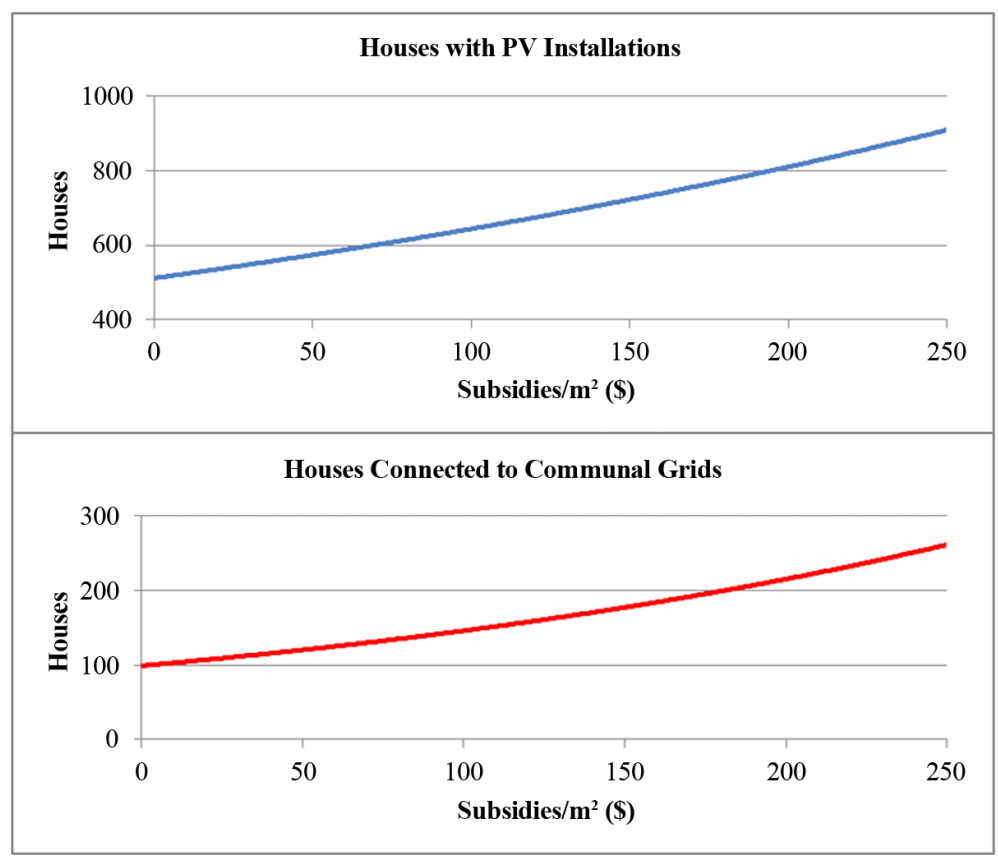

Figure 4. Effects of subsidies $/ \mathrm{m}^{2}$ on PV and communal grids diffusions.

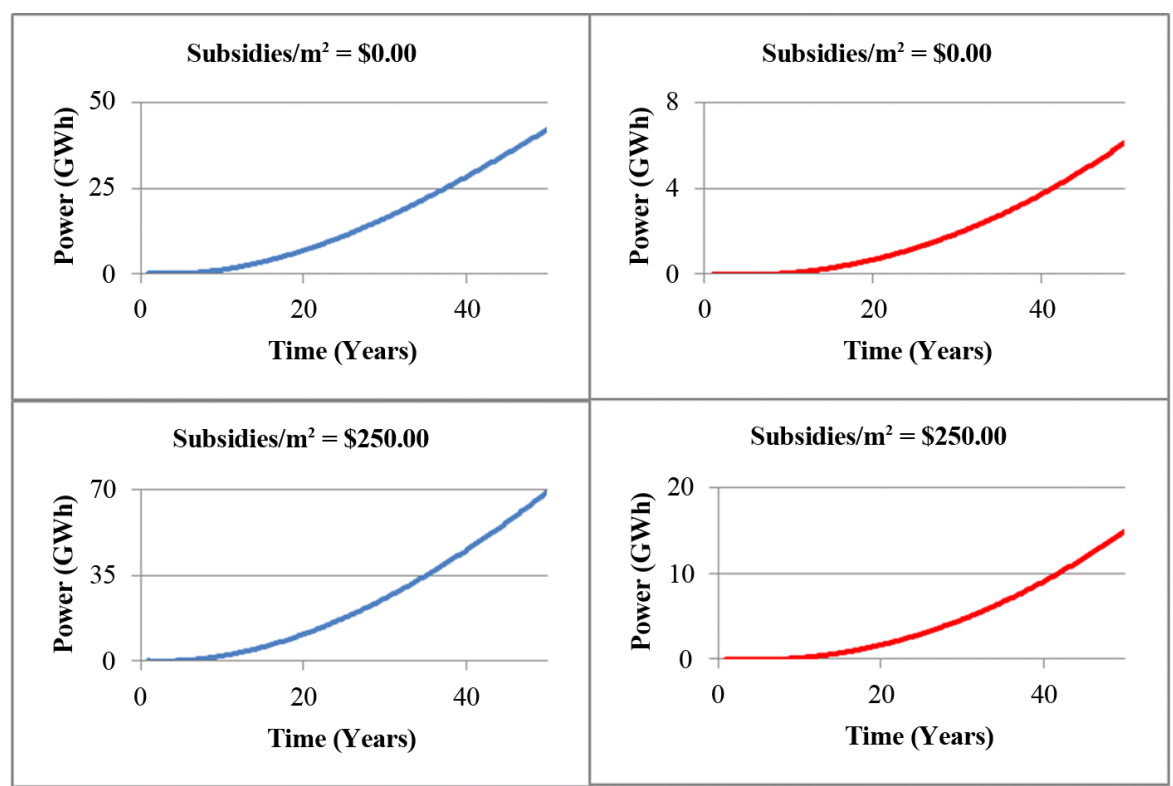

Figure 5. Temporal growths in power outputs from PV (blue) and communal grids (red).

generate about $15.1 \mathrm{GWh}$ of electricity, representing an increase of $147.5 \%$ in power output. The huge increase in power output from communal grids point to increase in installed PV capacities for those joining communal grids. These results further validate impacts of subsidies $/ \mathrm{m}^{2}$ on PV installations, and on subsequent communal grids formations and connections.

\subsection{Neighbourhood Influence}

Rogers' theory of Diffusions of Innovations (DOI) states that diffusion of a new technology into a given market depends on its relative advantage, compatibility, ease of use, and social acceptance amongst other factors [12]. According to this theory, different attitudes towards the new technology affect initial adoption rates, with more 
acceptances experienced with time after observations of the benefits of the new technology have been made [12]. Studies show that social acceptance is crucial to successful dissemination of a new technology, and this even more so with PV systems which impact on individuals' spaces both passively and actively [13]-[15]. An individual's willingness to participate in the microgeneration process through financial investment, provision of an installation site, or through behavioural change is important for successful uptake of such technologies [16]. Attitudes towards microgeneration technologies govern their social acceptances; in developed nations consumers are motivated by autonomy, interest in the new technology, environmental concerns, and economic reasons [16]-[19]. In developing nations on the other hand, consumers are motivated by availability; people are in need of electricity irrespective of its source, microgeneration technologies just happen to be the most readily available and cost-effective means of achieving that. In many cases, the environment is an unintended beneficiary.

A major factor in social acceptance is neighbourhood influence. Knowledge of a new technology is necessary for a consumer to make an informed decision on its adoption, but this is difficult with nascent technologies such as PV where information is asymmetrical, with producers being in better positions to test the technology than consumers, contributing to their initial slow diffusions in new markets [20]-[23]. In such cases, neighbourhood influence from early and independent adopters play important roles in increased future adoption rates [24]-[26]. Bollinger and Gillingham argue that neighbourhood influence begins to play a more important role once early adopters have installed a new technology [27]; they infer that visibility of a new technology (PV installed on roofs) coupled with word-of-mouth about benefits of the new technology leads to increased adaptation within a given neighbourhood or sensing radius [21]. Weber and Rode researched on the impacts of observational learning, or visibility of a new technology, on adaptation of PV installations, while ignoring the effects of social interactions or word-of-mouth [27]. They found that, even though visibility played an important role in PV diffusion, its effect was more localized to immediate neighbours thus to a small sensing radius [27].

It is difficult to model the impacts of different non-quantitative social aspects on the adoption of a new technology. However, measurable parameter such as sensing-radius, the radius within which a household can "sense" its neighbours, and neighbourhood-threshold, the minimum percentage of neighbours within a given sensing radius that must have adopted a new technology for a household to consider doing the same, can be modelled and varied to explore the impacts of such parameters in the adaptation of a new technology. If we assign a coefficient of innovation $p$ to early adopter and a coefficient of imitation $q$ to neighbourhood influence, the probability that a household deciding on PV installation actually adopts at time $t$ is given by [28]

$$
(p+q F(t))
$$

where $F(t)$ is the proportion of adopters at time $t$. Without neighbourhood influence, $p>0, q=0$, while without early adopters $p=0, q>0$.

The probability density function for a house that is deciding on PV installation at a time $t$ is given by

$$
f(t)=(p+q F(t))(1-F(t)) .
$$

And the corresponding cumulative density function is given by

$$
F(t)=\frac{1-\exp (-(p+q) t)}{1+\frac{q}{p} \exp (-(p+q) t)} .
$$

Given a market potential factor $m$, cumulative adoption of PV at a time $t$ is given by $F(t) \times m$. Coefficients $p$ and $q$, and market factor $m$ are considered environmental variables to account for the changing and unstable environment within which diffusion of a new technology occurs. Initial and independent adoption decisions are mainly influenced by perceived or measured costs, social pressures such as advertising campaigns, a level of awareness of the new technology, attitude towards the new technology such as environmental concerns in case of PV, and social demographics such as education and income levels. These factors are captured in the coefficient of innovation $p$. Perceived and spoken (word-of-mouth) benefits of the new technology are captured in the coefficient of imitation $q$. Geographical factors such as location and demographics will determine the market saturation levels which are then captured in the market potential factor $m$. Preferences for specific product attributes such as cost and environmental benefits can influence adoption timing decisions of new technologies as 
reported in studies by Kim and Srinivasan [29] and by Islam and Meade [30].

\subsubsection{Sensing Radius}

Figure 6 shows a comparison of houses with PV and houses that are connected to communal grids as functions of increasing sensing radius.

Sensing radius is the neighbourhood radius within which a household can be influenced by occurrences in other households. For example, a household can decide to install PV because they have observed a neighbour within the same radius having installed PV or because they have heard about the benefits of PV through word of mouth from neighbours within the sensing radius. Households that install PV without neighbourhood influence are called early or independent adopters. After 50 years, about 298 independent adopters would have installed $\mathrm{PV}$, representing $11.9 \%$ of all households. If s sensing radius of $1 \mathrm{~km}$ is introduced, the number of PV installations jump to 389, representing a 30.5\% increase in PV installations as a result of sensing radius (neighbourhood) influence. With a sensing radius of $2.5 \mathrm{~km}$, total PV installations increase to about 554, representing an increase of $85.9 \%$ in PV installations. A similar trend is observed in houses connecting to communal grids with about 68 independent adopters having been connected to communal grids after 50 years. This represents $22.8 \%$ of all early or independent adopters. With a sensing radius of $1 \mathrm{~km}$, this number jumps to 81, representing an increase of $19.1 \%$. With a sensing radius of $2.5 \mathrm{~km}, 98$ households would have connected to communal grids, representing an increase of $44.1 \%$. It is therefore evident that as sensing radius increases so does neighbourhood influence and thus increasing PV installations and subsequent communal grids connections.

\subsubsection{Neighbourhood Threshold}

Neighbourhood threshold is the minimum percentage of neighbours within a given sensing radius who must have installed PV for a household to develop the same idea. As mentioned above, households that develop the idea and install PV without the influence of others are called early adopters. Figure 7 shows a comparison of houses with PV and houses that are connected to communal grids as a function of increasing neighbourhood threshold.

PV installations and subsequent communal grids connections logarithmically decay with increasing neighbourhood threshold. This is explained by the fact that initially, only $0.1 \%$ of the population are seeded with PV. It would therefore take a while for factors such as neighbourhood influence to kick in before PV installations begin to spread widely. Requiring a higher percentage of households within a given neighbourhood to have installed PV

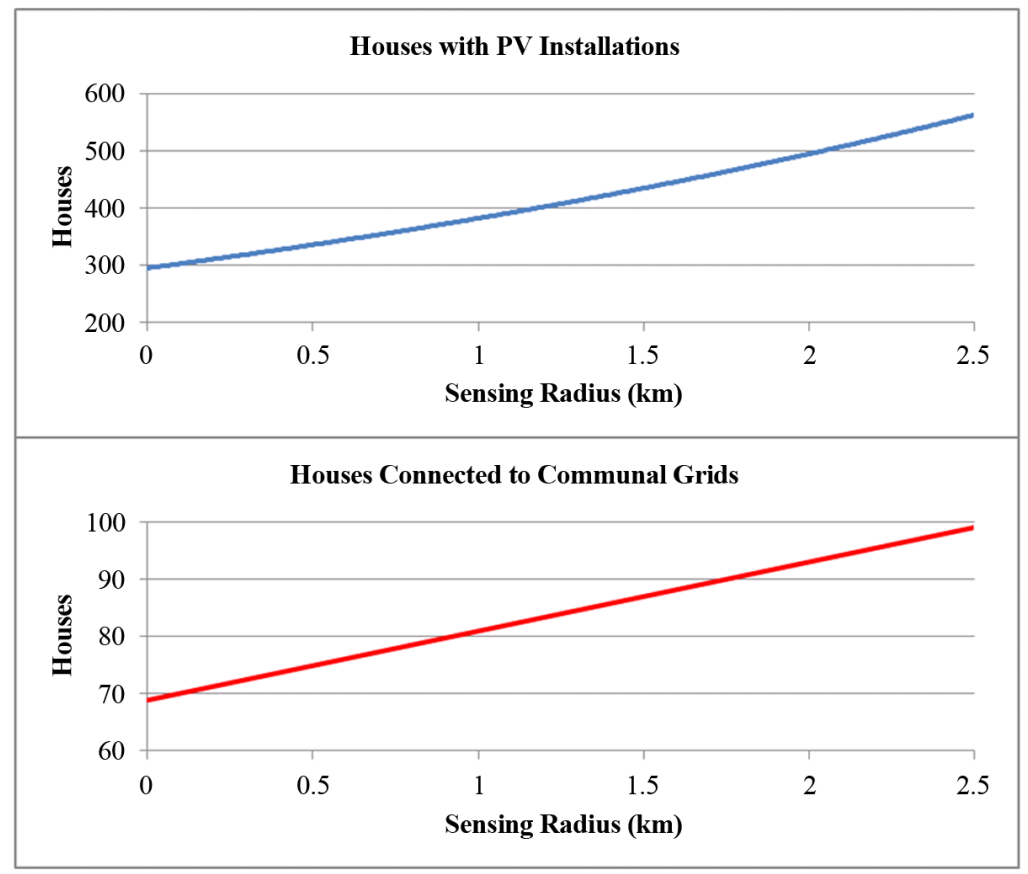

Figure 6. Effects of sensing radius on PV and communal grids diffusions. 


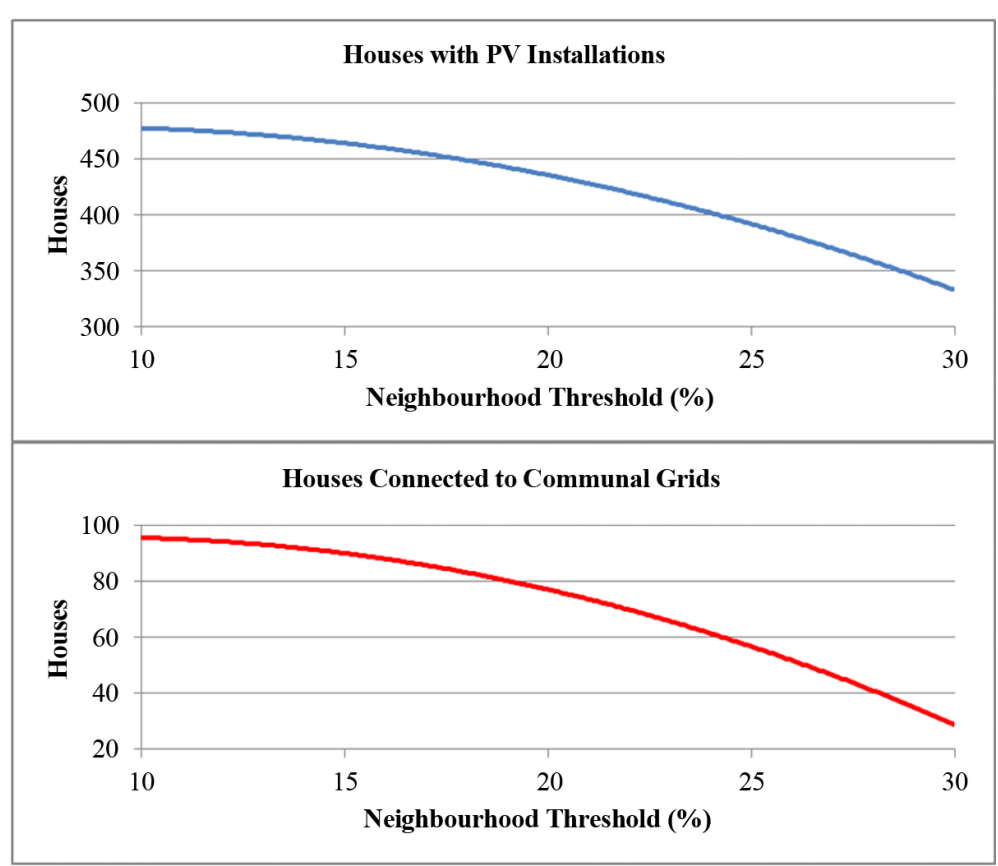

Figure 7. Effects of neighbourhood threshold on PV and communal grids diffusions.

before a given household can consider doing the same therefore leads to diminishing installations. With a neighbourhood threshold of $10 \%$, about 480 households would have installed PV after 50 years, representing $19.2 \%$ of all households. With a neighbourhood threshold of $20 \%$, this number falls to 432 , representing a drop of $12 \%$. Similarly, with a neighbourhood threshold of $30 \%$, the number of households with PV installations falls even further to 338, representing a $29.6 \%$ drop in PV installations. Similarly, with a $10 \%$ neighbourhood threshold, the number of households connected to communal grids after 50 years is about 95 , representing $19.8 \%$ of houses with PV. This number falls to about 77 , representing an $18.9 \%$ drop in communal grid connections. At $30 \%$ neighbourhood threshold, this number falls even further to 33 , representing $65.3 \%$ drop on communal grid connections.

In conclusion therefore, increasing sensing radius (neighbourhood influence) stimulate PV installations while increasing neighbourhood threshold leads to fall in PV installations.

\subsection{Impacts of Lending Rates on PV Diffusions}

Most PV systems installed by households in rural developing communities are small systems with capacities of between $20 \mathrm{Wp}$ and $100 \mathrm{Wp}$ mainly due to basic demands for power. Most of these systems are usually bought on cash basis because they are affordable and also due to lack of proper credit facilities to carter for low-income households. To stimulate rural commercial growth however, electricity-beyond-lighting is required and this can only be provided through grid electrification. In such cases, larger systems would need to be installed by households to sustain the grid. Such large systems are not easily affordable and thus the need for proper credit facilities; in this section the impacts of lending rates on formations of communal grids are explored.

Figure 8 shows a comparison of houses with PV installations and houses connected to communal grids as functions of increasing lending rates. Both plots exponentially decay, with houses with PV falling to zero for lending rates above $6 \%$ while houses connected to communal grids fall to zero for lending rates above $3.5 \%$. This means that as lending rates increase, loans become less attractive and only cash buyers opt for PV installations. However, cash buyers are few due to low income levels in many rural developing communities meaning their numbers in a given neighbourhood are too low and probably too sparse to warrant formations of communal grids. Also, cash buyers usually opt for affordable basic systems, for lighting and to power small electronic appliances such as phone chargers, and would not be willing to make huge investments into communal grids without proper incentives. 


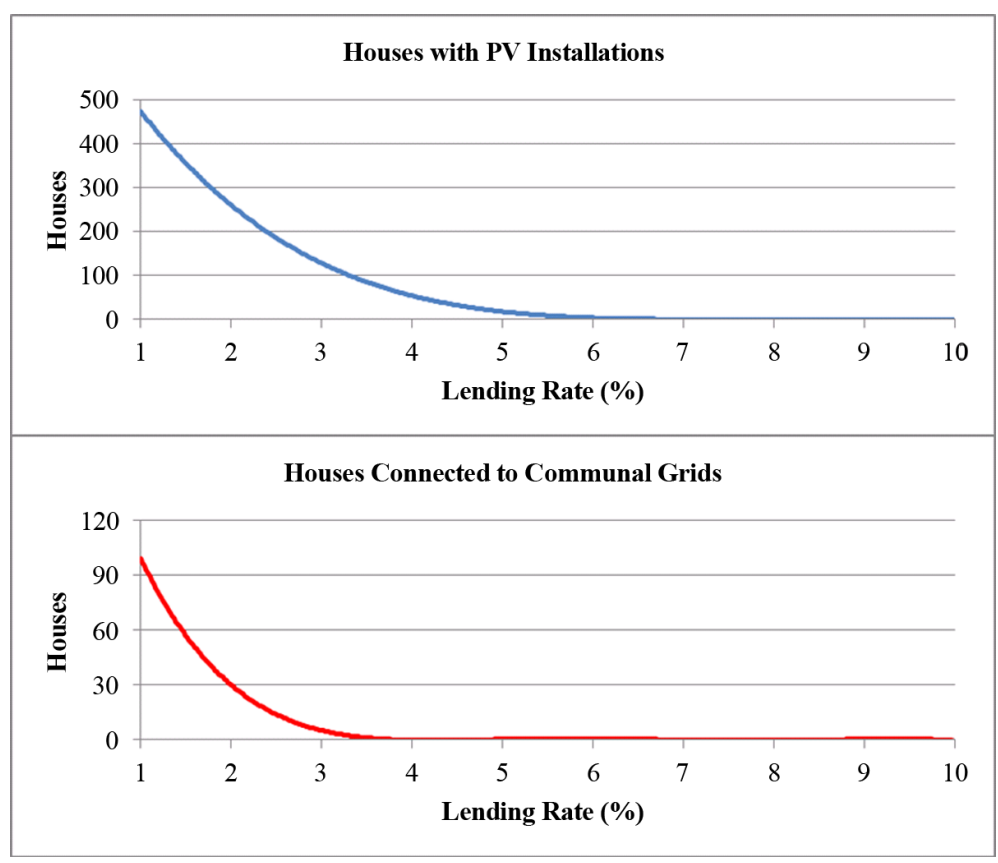

Figure 8. Effects of lending rates on PV and communal grids diffusions.

Commercial establishments need to be able to recover the costs of lending to consumers in reasonable times and it would be unbeneficial to lend at no interest. This explains why very few commercial financial institutions are willing to lend for PV installations. A solution lies in guarantees from the governments and in government funded microcredit facilities to offer low interest rates. Another solution is interest free hire-purchase arrangements; a store owner who estimates that it take 6 months to sell a single SHS unit could decide to attract more buyers buy offering customers the option to pay for a single unit in 6 equal and interest-free monthly instalments. This way, more people get to own SHS while at the same time, the store owner realizes increased sales.

Figure 9 shows a comparison of temporal growth in power outputs from households with PV and from households connected to communal grids as functions of increasing lending rates. After 50 years, about 45.17 GWh of electricity would be generated by households with PV if the lending rate was kept constant at $0 \%$ while at $2.5 \%$ lending rate, about $11.53 \mathrm{GWh}$ would be generated. Similarly, at $0 \%$, nearly $7 \mathrm{GWh}$ would be generated by communal grids after 50 years while at $2.5 \%$ only about $230 \mathrm{kWh}$ would be generated. These figures are indicative of rapidly falling numbers of houses installing PV systems as results of increasing lending rates; PV installations fall to zero for lending rates above 6\%. Falling PV installations translate into falling communal grid connections, falling to zero for interest rates above $3.5 \%$.

\subsection{Impacts of PV Costs and Grid Electricity Costs on PV Diffusions}

Advancements in research and development have seen massive improvements in both efficiencies and power outputs of PV systems, leading to falling costs of delivered electricity. This, coupled with generally increasing grid electricity costs, has led to rapid rises in installed PV power systems as alternatives to conventional fossil-fuel-based systems. In this Section, impacts of falling PV costs and generally increasing utility grid electricity costs are simulated.

\subsubsection{Falling PV Costs}

As mentioned above, decades of research and development have enabled efficient, rapid, and mass production of high quality PV systems, which have in turn translated into continuously falling prices of PV systems [31]. Figure 10 shows a comparison of households with PV installations and of households connected to communal grids as functions of falling PV costs.

Currently, PV costs about $\$ 300 / \mathrm{m}^{2}$ in East Africa. If these values were maintained for the next 50 years, PV installations will increase from an initial 3 to about 426. Even though this is a massive growth, better growth 


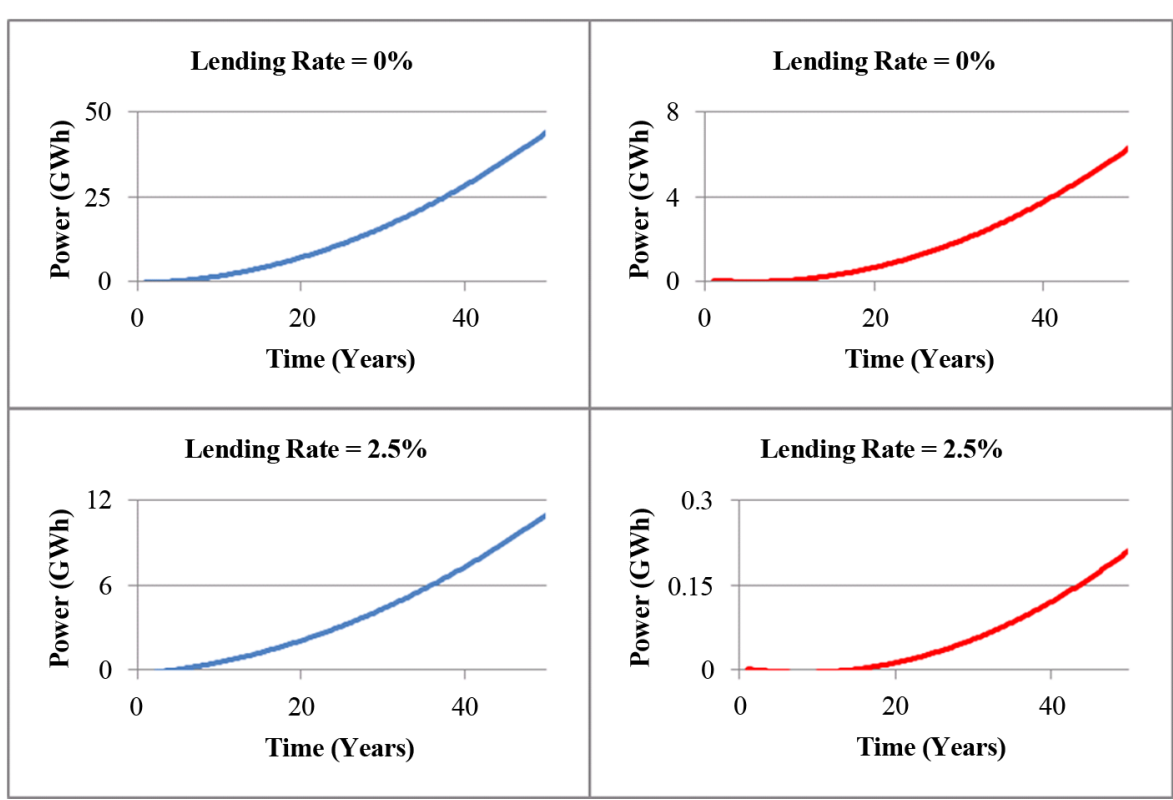

Figure 9. Temporal growths in power outputs from PV (blue) and communal grids (red).

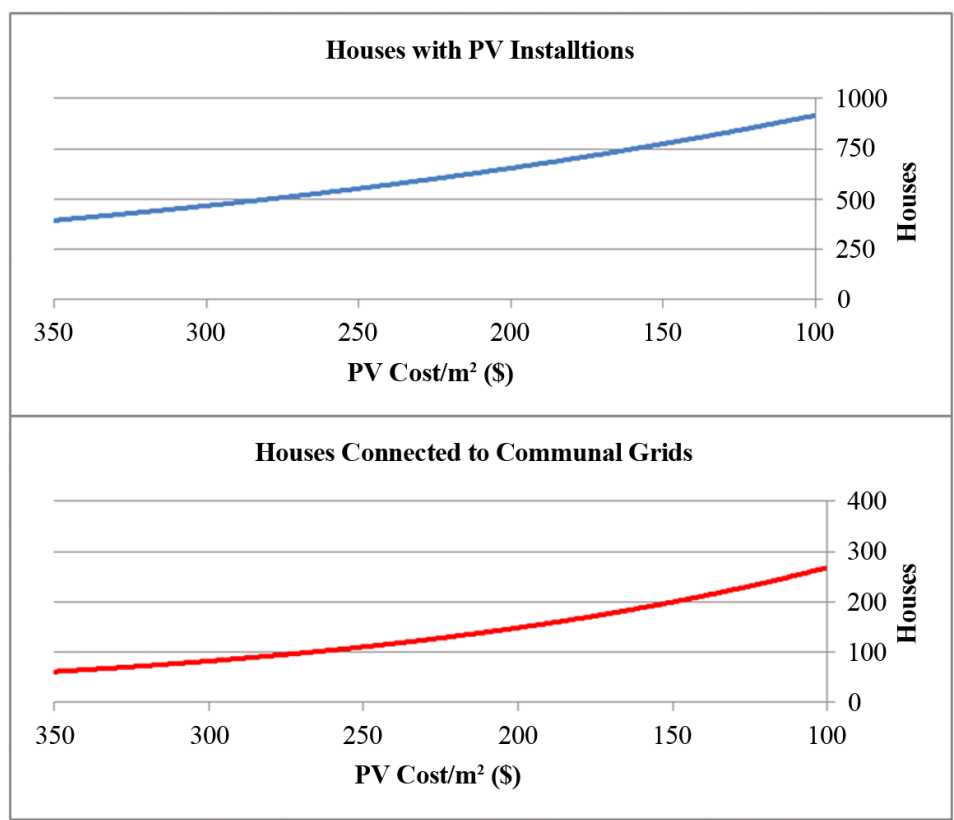

Figure 10. Effects of falling PV costs on PV and communal grids diffusions.

would be achieved with lower PV costs with PV costs of $\$ 200 / \mathrm{m}^{2}$ leading to $690 \mathrm{PV}$ installations, a $62 \%$ increase from PV costs of $\$ 300 / \mathrm{m}^{2}$. PV costs of $\$ 100 / \mathrm{m}^{2}$ would lead to 909 installations, a $113.4 \%$ increase from PV costs of $\$ 300 / \mathrm{m}^{2}$. Similarly, PV costs of $\$ 300 / \mathrm{m}^{2}$ would lead to about 60 communal grid connections after 50 years. PV costs of $\$ 200 / \mathrm{m}^{2}$ would lead to 164 communal grid connections, a $173.3 \%$ increase from PV costs of $\$ 300 / \mathrm{m}^{2}$. PV costs of $\$ 100 / \mathrm{m}^{2}$ would lead to 280 communal grid connections, a $366.7 \%$ increase from PV costs of $\$ 300 / \mathrm{m}^{2}$. Falling PV costs therefore lead to exponential growths in PV installations which translate into exponential growths in connections to communal grids.

\subsubsection{Increasing Grid Electricity Costs}

Utility grid electricity costs must inevitably increase due to many factors including increasing inflations, in- 
creasing transmission and distribution costs, increasing operations and management costs, losses due to theft, faults, etc., and increasing human capital costs. This, coupled with rapidly falling PV costs has led to a boom in PV installations, as mentioned above. Figure 11 shows a comparison of households with PV installations and of households connected to communal grids as functions of increasing utility grid costs.

The number of households installing PV and connecting to communal grids logarithmically grows with increasing grid electricity costs. Grid parity has been reached in many regions with PV systems and it is expected that this would be universal in the near future. It is therefore understandable that as grid costs rise, people will look for alternative energy sources elsewhere. Moreover, as global warming awareness increases, more people will feel the social pressure to look for cleaner and sustainable sources of electricity, and as has been discussed previously, decentralized generation systems based on locally available renewable energy resources, in this case solar, are the most promising alternatives.

\subsection{Impacts of Minimum Power Threshold on PV Diffusions}

Power threshold is the minimum power capacity of a PV system that a household must have installed or is willing to install (contribute towards the communal grid) before being allowed to join a communal grid. Since a communal grid is a connection of neighbours with PV systems within a given sensing radius, it is necessary to meet a certain load demand, and to do so, every household that joins the grid must be willing a make a given minimum investments in form of minimum PV capacity. Figure 12 shows a plot of houses with PV that are connected to communal grids a function of increasing power threshold; increasing the minimum power output that a household must be willing to bring to a communal grid leads to fewer houses joining the same. Most of the people installing PV systems can only afford small systems for basic lighting etc., requiring them to install larger systems, without some kind of credit arrangement, with therefore make communal girds out of reach of many potential consumers.

The temporal plots in Figure 13 confirm the above observations. With a power threshold of 2000 W, 399 households will have connected to communal grids after 50 years. This number reduces to 311 for a power threshold of $3000 \mathrm{~W}$, representing a $22.1 \%$ drop in connections. If the power threshold was $4000 \mathrm{~W}$, the number of communal grid connections after 50 years would be 179 , representing a $55.1 \%$ drop in connections. A power threshold of $5000 \mathrm{~W}$ would result in 83 connections after 50 years, representing a 79.2\% drop in communal grid connections. Therefore a balance has to be struck between minimum investments required to join a communal

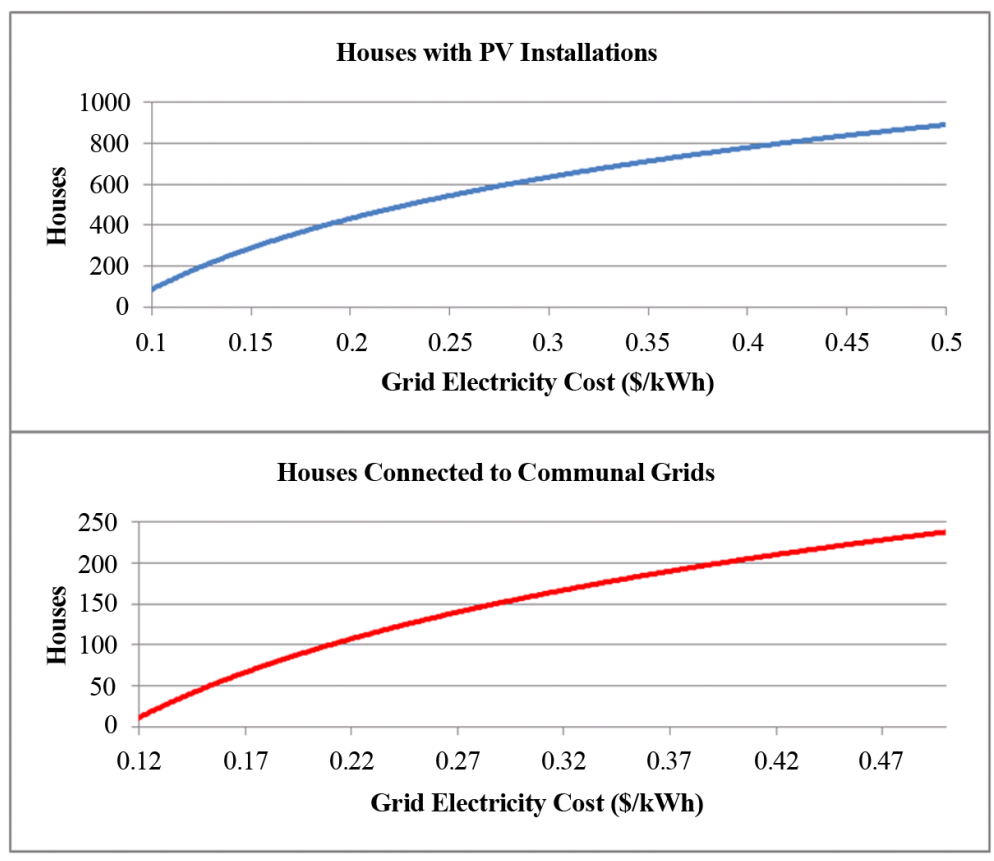

Figure 11. Effects of increasing grid electricity costs on PV and communal grids diffusions. 
Effects of Power Threshold on Communal Grids Connections

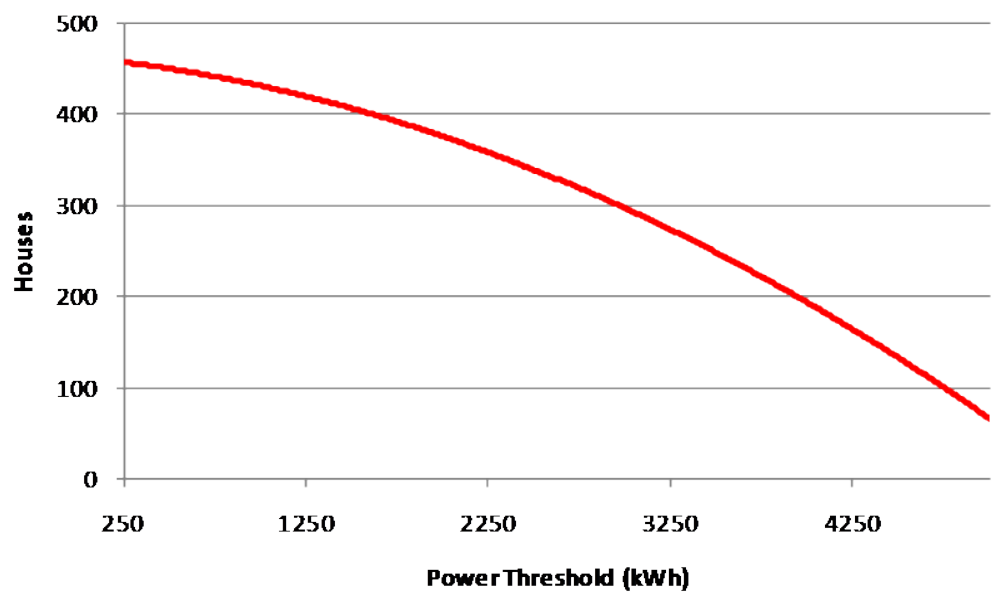

Figure 12. Power threshold vs. houses connected to communal grids.

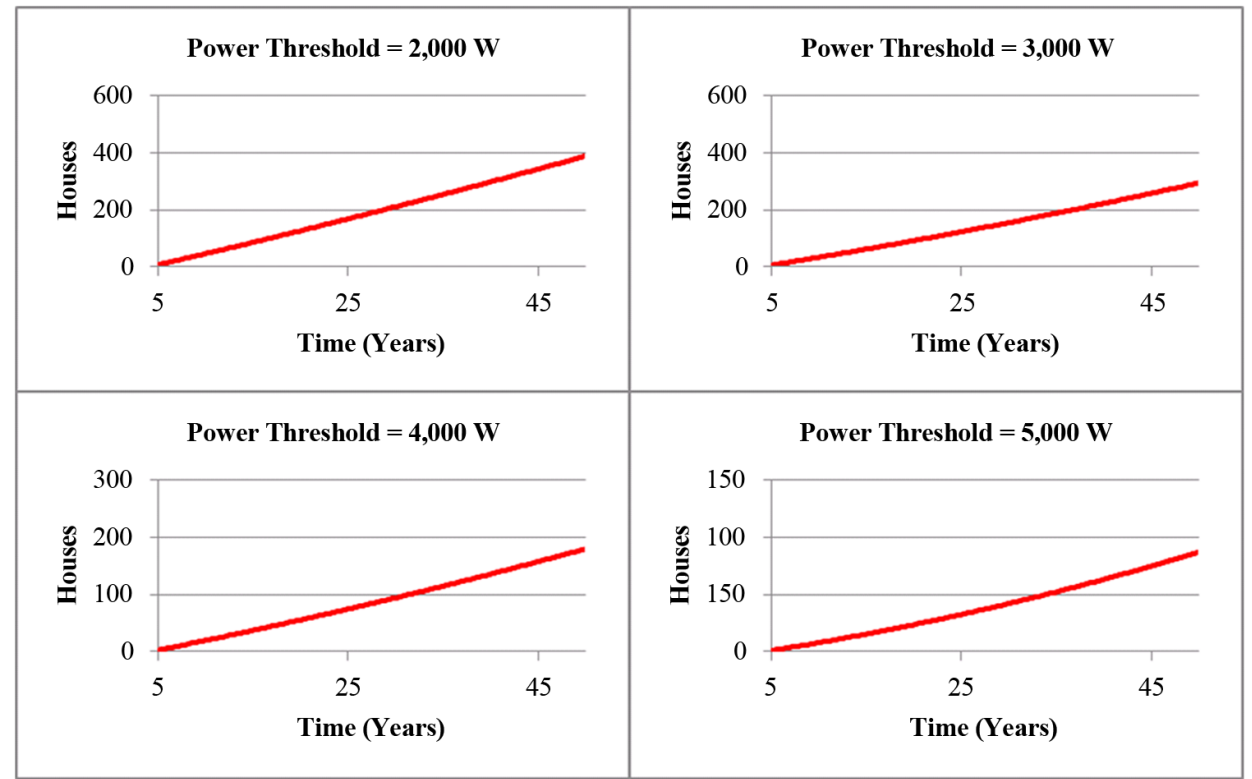

Figure 13. Comparison of temporal diffusion of communal grids at different power thresholds.

grid and the potential customer base.

\section{Conclusions}

In this chapter, effects of socio-economic and technical factors on the diffusions of PV-based communal grids in a typical rural developing community have been modelled and simulated using an agent-based model developed in Netlogo. The following observations have been made:

- Rapidly falling PV costs coupled with generally increasing utility grid electricity costs stimulate PV installations and subsequent communal grid formations and connections.

- Increments in minimum power threshold required for a house to join a communal grid lead to lower rates of grid connections. This is because most of the modelled households have basic electricity needs and thus small installed PV systems. Requiring them to install bigger systems before joining communal grids is a dissuading factor.

- Increasing lending rates lead to falling PV installations which in turn translate into falling communal grid connections; PV installations based on loans fall to zero for lending rates above 6\% while connections to com- 
munal grid fall to zero for lending rates above $3.5 \%$.

- Subsidies stimulate PV installations which in turn stimulate formations of communal grids.

- Increasing sensing radii lead to increasing PV installations which in turn lead to increasing formations of communal grids.

- Increasing neighbourhood threshold leads to decreasing PV installations and also to decreasing formations of communal grids.

In conclusion therefore, developing communities should strive to introduce positive incentives in forms of subsidies and affordable credit facilities to stimulate PV installations. Neighbourhood influence on a household's energy choices is evidently strong and this increases with increasing sensing radius, it is therefore important to establish a strong marketing strategy and after-sales services to encourage more PV installations because a bad publicity can easily lead to diminishing installations. Households within a given sensing radius willing to come together to form a communal grid should strike a balance between conditions required to join such a grid and the potential that benefits a new member will bring to the grid. A good minimum investment into the grid should be calculated based on the number of members to be served, load demands, cost of establishing the network, and other costs such as operations and maintenance costs etc. This would enable more people to make investments into the grid, with a promise of access to more power, thus stimulating local economy. The model developed in this chapter can be easily modified and used to predict future electrification topologies of a given area given socio-economic demographics and geographical data. The results of such simulations could be used for rural electrification policy formulations and for planning and implementing rural electrification projects.

\section{Acknowledgements}

This research is by Leeds International Research Scholarship.

\section{References}

[1] Parshall, L., Pillai, D., Mohan, S., et al. (2009) National Electricity Planning in Settings with Low Pre-existing Grid Coverage: Development of a Spatial Model and Case Study of Kenya. Energy Policy, 37, 2395-2410. http://dx.doi.org/10.1016/j.enpol.2009.01.021

[2] Sanoh, A., Parshall, L. Sarr, O., et al. (2012) Local and National Electricity Planning in Senegal: Scenarios and Policies. Energy for Sustainable Development, 16, 13-25. http://dx.doi.org/10.1016/j.esd.2011.12.005

[3] Levin, T. and Thomas, V. (2012) Least-Cost Network Evaluation of Centralized and Decentralized Contributions to Global Electrification. Energy Policy, 41, 286-302. http://dx.doi.org/10.1016/j.enpol.2011.10.048

[4] Foster, V. and Steinbuks, J. (2009) Paying the Price for Unreliable Power Supplies In-House Generation of Electricity by Firms in Africa. WPS.

[5] Bhattacharyya, S. and Timilsina, G. (2010) Modelling Energy Demand of Developing Countries: Are the Specific Features Adequately Captured? Energy Policy, 38, 1979-1990. http://dx.doi.org/10.1016/j.enpol.2009.11.079

[6] Urban, F., Benders, R. and Moll, H. (2007) Modelling Energy Systems for Developing Countries. Energy Policy, 35, 3473-3482. http://dx.doi.org/10.1016/j.enpol.2006.12.025

[7] Zhao, J., Mazhari, E., Celik, N. and Son, Y. (2011) Hybrid Ahent-Based Simulation for Policy Evaluation of Solar Power Generation Systems. Simulation Modelling Practice and Theory, 19, 2189-2205. http://dx.doi.org/10.1016/j.simpat.2011.07.005

[8] Beise, M. (2004) The International Adoption of Photovoltaic Energy Conversion: Is Japan a Lead Market? Discussion Paper Series 153, Research Institute for Economics \& Business Administration, Kobe University.

[9] Guidolin, M. and Mortarino, C. (2010) Cross-Country Diffusion of Photovoltaic Systems: Modelling Choices and Forecasts for National Adoption Patterns. Technological Forecasting and Social Change, 77, 279-296. http://dx.doi.org/10.1016/j.techfore.2009.07.003

[10] Wustenhagen, R. and Bilharz, M. (2006) Green Energy Market Development in Germany: Effective Public Policy and Emerging Customer Demand. Energy Policy, 34, 1681-1696. http://dx.doi.org/10.1016/j.enpol.2004.07.013

[11] Zhang, Y., Song, J. and Hamori, S. (2011) Impact of Subsidy Policies on Diffusion of Photovoltaic Power Generation. Energy Policy, 39, 1958-1964. http://dx.doi.org/10.1016/j.enpol.2011.01.021

[12] Rogers, E. (2003) Diffusion of Innovations. Free Press, New York.

[13] Sauter, R. and Watson, J. (2007) Strategies for the Deployment of Micro-Generation Implications for Social Acceptance. Energy Policy, 35, 2770-2779. http://dx.doi.org/10.1016/j.enpol.2006.12.006 
[14] Semadeni, M., Hansmann, R. and Flueeler, T. (2004) Public Attitudes in Relation to Risk and Novelty of Future Energy Options. Energy \& Environment, 15, 755-777. http://dx.doi.org/10.1260/0958305042886787

[15] Kaldellis, J. (2005) Social Attitude towards Wind Energy Applications in Greece. Energy Policy, 33, 595-602. http://dx.doi.org/10.1016/j.enpol.2003.09.003

[16] Fischer, C. (2004) Users as Pioneers: Transformation in the Electricity System, Micro CHP and the Role of the Users. In: Jacob, K., Binder, M. and Wieczorek, A., Eds., Governance for Industrial Transformation, Proceedings of the 2003 Berlin Conference on Human Dimensions of Global Environmental Change, Environmental Policy Research Centre, Berlin, 319-337.

[17] Fischer, C. (2006) From Consumers to Operators: the Role of Micro CHP Users. In: Pehnt, M., Cames, M., Fischer, C., et al., Eds., Microgeneration: Towards a Decentralized Energy Supply, Springer, Heidelberg, 117-143.

[18] London Renewables (2003) Attitudes to Renewable Energy in London: Public and Stakeholder Opinion and the Scope for Progress. A Report Commission by London Renewables and Carried out by Brook Lyndhurst Ltd in Association with MORI and Upstream, Greater London Authority.

[19] Ellison, G. (2004) Renewable Energy Survey: Draft Summary Report of Findings. ORC International, London.

[20] Young, H. (2009) Innovation Diffusion in Heterogeneous Populations: Contagion, Social Influence, and Social Learning. The American Economic Review, 99, 1899-1924. http://dx.doi.org/10.1257/aer.99.5.1899

[21] Bollinger, B. and Gillingham, K. (2012) Peer Effects in the Diffusion of Solar Photovoltaic Panels. Marketing Science, 31, 800-812. http://dx.doi.org/10.1287/mksc.1120.0727

[22] Narayanan, S. and Nair, H. (2012) Estimating Causal Installed-Base Effects: A Bias-Correction Approach.

[23] Rai, V. and Robinson, S. (2013) Effective Information Channels for Reducing Costs of Environmentally Friendly Technologies: Evidence from Residential PV Markets. Environmental Research Letters, 8, Article ID: 014044. http://dx.doi.org/10.1088/1748-9326/8/1/014044

[24] Jaffe, A., Newell, R. and Stavins, R. (2005) A Tale of Two Market Failures: Technology and Environmental Policy. Ecological Economics, 54, 164-174. http://dx.doi.org/10.1016/j.ecolecon.2004.12.027

[25] Brown, J. and Reingen, P. (1987) Social Ties and Word-of-Mouth Referral Behaviour. Journal of Consumer Research, 14, 350-362. http://dx.doi.org/10.1086/209118

[26] Krishnamurthy, S. (2001) A Comprehensive Analysis of Permission Marketing. Journal of Computer Mediated Communication, 6. http://dx.doi.org/10.1111/j.1083-6101.2001.tb00119.x

[27] Rode, J. and Weber, A. (2011) Knowledge Does Not Fall Far from the Tree-A Case Study on the Diffusion of Solar Cells in Germany. ERSA Conference Papers ERSA 11 p 497, European Regional Science Association.

[28] Bass, F. (1969) A New Product Growth Model for Consumer Durables. Management Science, 15, 215-227. http://dx.doi.org/10.1287/mnsc.15.5.215

[29] Kim, S.-H. and Srinivasan, V. (2009) A Conjoint-Hazard Model of the Timing of Buyers' Upgrading to Improved Versions of High-Technology Products. Journal of Product Innovation Management, 26, 278-290. http://dx.doi.org/10.1111/j.1540-5885.2009.00658.x

[30] Islam, T. and Meade, N. (2012) The Impact of Competition, and Economic Globalization on the Multinational Diffusion of 3G Mobile Phones. Technological Forecasting and Social Change, 79, 843-850. http://dx.doi.org/10.1016/j.techfore.2012.01.002

[31] Earth Policy Institute (2015). http://www.earth-policy.org/data_center/C23 